\title{
Global burden of COPD: systematic review and meta-analysis
}

\author{
R.J. Halbert*\#, J.L. Natoli*, ${ }^{\star}$, A. Gano*, E. Badamgarav*, A.S. Buist ${ }^{+}$and \\ D.M. Mannino ${ }^{\xi}$
}

ABSTRACT: The aim of this study was to quantify the global prevalence of chronic obstructive pulmonary disease (COPD) by means of a systematic review and random effects meta-analysis.

PubMed was searched for population-based prevalence estimates published during the period 1990-2004. Articles were included if they: 1) provided total population or sex-specific estimates for COPD, chronic bronchitis and/or emphysema; and 2) gave method details sufficiently clearly to establish the sampling strategy, approach to diagnosis and diagnostic criteria.

Of 67 accepted articles, 62 unique entries yielded 101 overall prevalence estimates from 28 different counties. The pooled prevalence of COPD was $7.6 \%$ from 37 studies, of chronic bronchitis alone (38 studies) was $6.4 \%$ and of emphysema alone (eight studies) was $1.8 \%$. The pooled prevalence from 26 spirometric estimates was $8.9 \%$. The most common spirometric definitions used were those of the Global Initiative for Chronic Obstructive Lung Disease (13 estimates). There was significant heterogeneity, which was incompletely explained by subgroup analysis (e.g. age and smoking status).

The prevalence of physiologically defined chronic obstructive pulmonary disease in adults aged $\geqslant 40 \mathrm{yrs}$ is $\sim 9-10 \%$. There are important regional gaps, and methodological differences hinder interpretation of the available data. The efforts of the Global Initiative for Chronic Obstructive Lung Disease and similar groups should help to standardise chronic obstructive pulmonary disease prevalence measurement.

KEYWORDS: Chronic bronchitis, chronic obstructive pulmonary disease, emphysema, metaanalysis, prevalence, spirometry

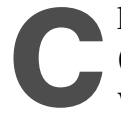
hronic obstructive pulmonary disease (COPD) is a leading cause of death worldwide [1]. In addition to generating high healthcare costs [2], COPD imposes a significant burden in terms of disability and impaired quality of life [3]. Unlike many leading causes of death and disability, COPD is projected to increase in much of the world as smoking frequencies rise and the population ages [4,5]. Despite the importance of this disease, the general perception is that the prevalence of COPD is not well measured. Accurate prevalence information is important for several reasons, including documentation of COPD's impact on disability, quality of life and costs, and for helping to inform public health planning [6]. It is also important to establish baseline prevalence rates so that researchers can monitor trends, including the success or failure of control efforts.

Previous publications have reviewed the literature qualitatively, but not quantitatively $[7,8]$.
These reviews identified potential sources of interstudy variation that could affect reported prevalence estimates. Historically, COPD has been defined symptomatically as chronic bronchitis (CB), anatomically as emphysema, or, most recently, physiologically as airway obstruction [9]. The physiological definition has become the most common [10,11], although studies using other case definitions are still published. Even with growing consensus on the use of spirometry as a physiological criterion, spirometric cut-off points for establishing airflow obstruction differ significantly [12]. Since lung function declines with age, COPD prevalence estimates are highly dependent upon the age range and distribution of subjects included. As smoking is the primary risk factor for COPD, prevalence estimates may also vary by underlying smoking frequencies. With the rise in smoking frequencies in females, there are ongoing controversies as to the relative impact of smoking on the development of COPD in males and females. Finally, the contribution of other inhaled exposures (e.g. occupational smoke
AFFILIATIONS

${ }^{*}$ Center Life Sciences, Beverly Hills,

CA,

Depts of ${ }^{\#}$ Community Health

Sciences and

-Epidemiology, UCLA School of

Public Health, Los Angeles, CA,

${ }^{+}$Dept of Pulmonary and Critical Care

Medicine, Oregon Health and

Science University, Portland, OR,

${ }^{\S}$ Dept of Pulmonary and Critical Care

Medicine, University of Kentucky,

Lexington, KY, USA.

CORRESPONDENCE

R.J. Halbert

Center Life Sciences

9100 Wilshire Blvd

Suite 655E

Beverly Hills

CA 90212

USA

Fax: 18169361862

E-mail: rhalbert@cerner.com

Received:

October 252005

Accepted after revision:

March 252006

SUPPORT STATEMENT

This study was supported by Boehringer Ingelheim International (Ingelheim am Rhein, Germany). 
or dust, ambient air pollution, and biomass fuel) to population prevalence rates have yet to be determined for most countries.

In order to quantitatively describe the global burden of COPD prevalence, a systematic review and meta-analysis of the published medical literature was conducted.

\section{METHODS}

PubMed was searched for population-based prevalence estimates published during the period 1990-2004. The search terms included "chronic obstructive pulmonary disease", "COPD", "chronic bronchitis", "emphysema", "airway obstruction", "epidemiology" and "prevalence". Details of the search strategy are presented in Appendix 1.

Articles were included if they: 1) provided total population or sex-specific estimates for COPD, CB and/or emphysema; and 2) gave method details sufficiently clearly to establish the sampling strategy, approach to diagnosis and diagnostic criteria used by the investigators. Sampling strategy was assessed to determine whether or not the study could be generalised to the rest of the country or region (i.e. whether a representative sample of the population was selected). Studies that provided data on only specific subpopulations (e.g. smokers or occupational studies) were excluded, as were non-English language studies with duplicate publications in English.

Based on these explicit criteria, two researchers reviewed a random $10 \%$ sample of abstracts identified by the search strategy. Inter-rater agreement was assessed using the kappa statistic, and the remaining abstracts were split evenly between the reviewers once a sufficient level of agreement was achieved (kappa >0.7). The full text of all accepted publications was obtained and their content reviewed for final inclusion. NonEnglish language articles were translated into English. The references of all English language articles with primary or secondary COPD prevalence estimates were also reviewed in order to identify additional estimates that may have been missed by the initial search strategy.

For each accepted study, the following data, when available, were abstracted: author, year of publication, year of data collection, sample size, percentage prevalence (or number of COPD cases), age range and mean age of study subjects, percentage males, percentage smokers (combined smokers and ex-smokers), country, study setting (rural, urban or mixed), response rate, diagnosis (COPD, CB or emphysema), and diagnostic criterion (chronic productive cough, spirometry, patient-reported diagnosis, physician diagnosis or physical/ radiographic findings). Data were also collected on quality of study design and quality of data analysis, which were classified as good, average or poor. Information about spirometric quality was collected when appropriate. The guidelines used for assessing study quality are presented in Appendix 2.

For each study, sex-, smoking- and age-specific prevalence estimates were abstracted when reported. If not specifically reported, these estimates were calculated based on the data provided. For smoking status, estimates for smokers, exsmokers and nonsmokers were included. For consistency, estimates in which ex-smokers were combined with smokers or nonsmokers were excluded. Since the majority of studies did not report mean age, prevalence estimates were assigned to an age category based upon judgment of which age group was most appropriate. Age-specific estimates were grouped into two age categories with a cut-off of $40 \mathrm{yrs}$; the $\geqslant 40$-yrs age group was further subdivided into $40-64$ yrs and $\geqslant 65$ yrs.

For the meta-analysis, the conservative random-effects empirical Bayesian method of HeDGES and OLKIN [13] was used to pool the estimated effects. Within-group heterogeneity was evaluated using Cochran's Chi-squared test (also called the Q test) [14] and the I-squared statistic [15]. For the $Q$ test, significance was set at $\mathrm{p}<0.10$. For subgroup analyses, the heterogeneity between groups was also calculated using the $Q$ test. Since many studies provided multiple prevalence estimates using various definitions, double-counting from the same study was avoided by using a hierarchical ranking system based on diagnostic criteria (Appendix 3).

\section{RESULTS}

A detailed diagram of the review process is presented in figure 1. The initial search identified 5,464 studies of potential interest, including 978 non-English language articles. After title and abstract review, 5,108 studies were excluded. Of 356 studies meeting the initial inclusion criteria, 64 were accepted for data abstraction. Articles were excluded due to duplicate publication, lack of adequate data for meta-analysis or inclusion/exclusion criteria that made the study unrepresentative of the population. Three additional articles were identified through hand-searches of relevant bibliographies, bringing the total number of accepted articles to 67 .

Of 67 accepted articles, several studies presented data from the same study group or survey. In these cases, the data were merged, leaving a total of 63 unique entries in the metaanalysis. A total of 62 studies reported 101 overall prevalence estimates from 28 different counties, and one additional study

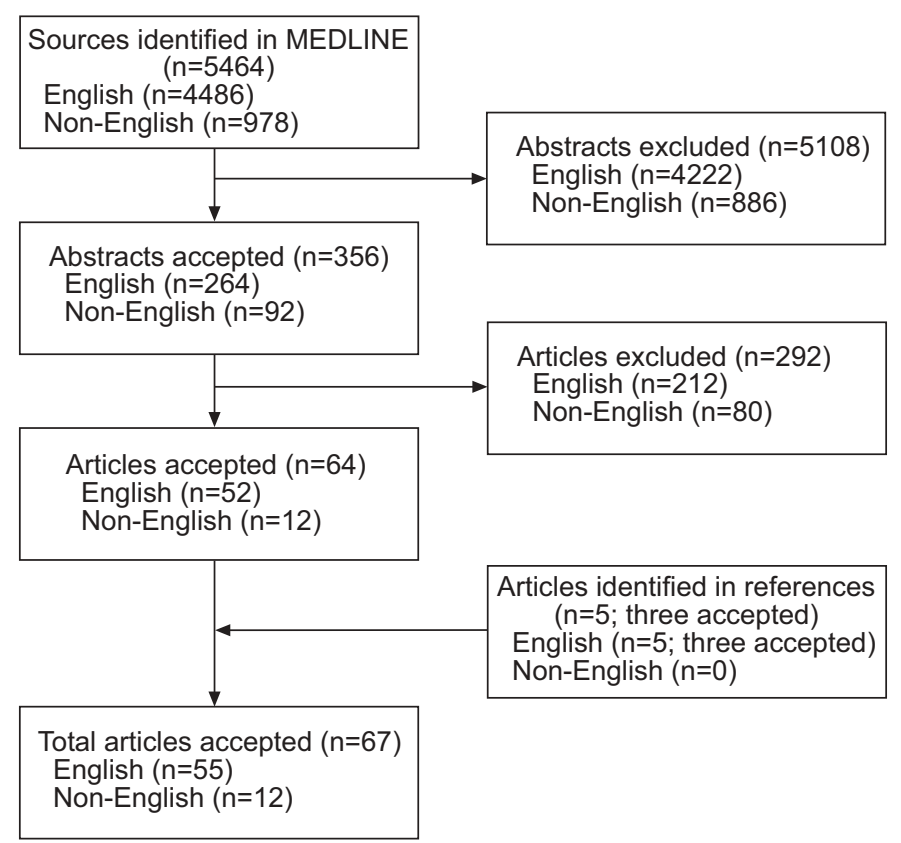

FIGURE 1. Chronic obstructive pulmonary disease prevalence studies identified in PubMed from 1990-2004. 
limited to females provided a sex-specific estimate (table 1). Two studies reported data collected as part of the European Community Respiratory Health Survey; these included data from multiple European countries. The 101 overall estimates included some duplicate estimates from the same study (e.g. patient-reported and spirometrically determined COPD).

Pooled prevalence estimates for all diagnostic groups are presented in table 2. After eliminating duplicate estimates from the same study, 37 estimates for COPD (including studies that reported a combined rate for $\mathrm{CB}$ and emphysema) yielded a pooled prevalence estimate of $7.6 \%$. Objective definitions tended to produce higher prevalence estimates than patientreported diagnoses. For example, spirometric criteria resulted in a higher prevalence estimate compared with patientreported COPD (9.2 versus $4.9 \%$, respectively). The pooled

\begin{tabular}{|c|c|c|c|}
\hline \multirow[t]{2}{*}{ TABLE 1} & \multirow[b]{2}{*}{ Country [Ref.] } & \multirow[b]{2}{*}{ Studies } & \multirow[b]{2}{*}{$\begin{array}{c}\text { Overall } \\
\text { estimates }\end{array}$} \\
\hline & & & \\
\hline Africa & South Africa [16] & 1 & 1 \\
\hline \multirow[t]{3}{*}{ Americas } & Brazil $[17,18]$ & 1 & 1 \\
\hline & Canada [19] & 1 & 1 \\
\hline & USA [20-23] & 4 & 6 \\
\hline \multirow{2}{*}{$\begin{array}{l}\text { Eastern Mediterranean } \\
\text { Europe }\end{array}$} & $\operatorname{Iran}{ }^{\bullet}[24]$ & 1 & 1 \\
\hline & Czech Republic $[25,26]$ & 2 & 2 \\
\hline & Denmark $[27,28]$ & 1 & 2 \\
\hline & Estonia $[29,30]$ & 2 & 4 \\
\hline & Finland [31-34] & $4^{+}$ & 9 \\
\hline & France $[35,36]$ & 2 & 2 \\
\hline & Italy [37-42] & 6 & 13 \\
\hline & Lithuania [43] & 1 & 2 \\
\hline & $\begin{array}{c}\text { Multiple countries } \\
{[444,45]}\end{array}$ & 2 & 3 \\
\hline & Norway [46] & 1 & 2 \\
\hline & Poland $[47,48]$ & 2 & 3 \\
\hline & Romania [49] & 1 & 1 \\
\hline & Russia [50] & 1 & 1 \\
\hline & Scotland [51] & 1 & 1 \\
\hline & Spain [52-55] & 4 & 7 \\
\hline & Sweden $[33,56-62]$ & $8^{+}$ & 16 \\
\hline & Switzerland [63-65] & 1 & 1 \\
\hline & Turkey [66] & 1 & 1 \\
\hline & UK [67-69] & 3 & 4 \\
\hline \multirow[t]{2}{*}{ South-East Asia } & India [70-73] & 4 & 4 \\
\hline & Thailand [74] & 1 & 1 \\
\hline \multirow[t]{4}{*}{ Western Pacific } & Australia [75] & 1 & 4 \\
\hline & China [76-78] & 3 & 5 \\
\hline & Japan [79] & 1 & 2 \\
\hline & South Korea [80] & 1 & 1 \\
\hline Total & & 62 & 101 \\
\hline
\end{tabular}

\#: includes duplicate estimates from the same study (e.g. patient-report and spirometry). ": a second study was limited to females and provided a sexspecific estimate only [81]; ${ }^{+}$: one study, conducted in both Sweden and Finland, is counted twice in the total number of studies [33]; ${ }^{\text {s: }}$ European Community Respiratory Health Survey.

\begin{tabular}{|c|c|c|c|c|}
\hline \multirow[t]{2}{*}{ TABLE 2} & \multicolumn{4}{|c|}{$\begin{array}{l}\text { Nonduplicated pooled prevalence estimates for } \\
\text { all diagnoses, including diagnostic criterion- } \\
\text { specific estimates }\end{array}$} \\
\hline & & $\begin{array}{c}\text { Estimates } \\
n\end{array}$ & $\begin{array}{c}\text { Prevalence } \\
\%\end{array}$ & $\begin{array}{c}\text { Pooled } \\
\text { prevalence \% }\end{array}$ \\
\hline \multicolumn{2}{|l|}{ COPD } & 37 & $8.9(2.1-26.4)$ & $7.6(6.0-9.5)$ \\
\hline \multicolumn{2}{|c|}{ Spirometry } & 26 & $10.1(2.1-26.4)$ & $9.2(7.7-11.0)$ \\
\hline \multicolumn{2}{|c|}{ Patient-reported diagnosis } & 7 & $3.7(3.0-10.5)$ & $4.9(2.8-8.3)$ \\
\hline \multicolumn{2}{|c|}{ Physician diagnosis } & 4 & $4.1(2.3-18.2)$ & $5.2(3.3-7.9)$ \\
\hline \multicolumn{2}{|c|}{ Physical/radiography } & 1 & & $13.7(12.9-14.5)$ \\
\hline \multicolumn{2}{|c|}{ Chronic Bronchitis } & 38 & $6.7(1.2-22.7)$ & $6.4(5.3-7.7)$ \\
\hline \multicolumn{2}{|c|}{ Symptoms ${ }^{\#}$} & 29 & $7.7(1.4-15.9)$ & $6.7(5.4-8.2)$ \\
\hline \multicolumn{2}{|c|}{ Patient-reported diagnosis } & 15 & $4.4(1.2-22.7)$ & $5.3(3.9-7.1)$ \\
\hline \multicolumn{2}{|c|}{ Emphysema } & 8 & $1.8(0.5-5.7)$ & $1.8(1.3-2.6)$ \\
\hline \multicolumn{2}{|c|}{ Physical/radiography } & 1 & & $3.2(2.8-3.6)$ \\
\hline \multicolumn{2}{|c|}{ Patient-reported diagnosis } & 7 & $1.5(0.5-5.7)$ & $1.7(1.2-2.5)$ \\
\hline
\end{tabular}

Prevalences are presented as median (range) and pooled prevalences as pooled prevalence estimate ( $95 \%$ confidence interval). COPD: chronic obstructive pulmonary disease. Heterogeneity within each stratum, as calculated by the $Q$ statistic, was significant for all strata with more than one estimate $(\mathrm{p}<0.0001)$. ${ }^{*}$ : chronic productive cough.

prevalence of CB alone was $6.4 \%$ from 38 studies. Eight studies reported emphysema alone, with a pooled prevalence of $1.8 \%$.

Diagnostic criteria for spirometry-based prevalence estimates from 26 studies are presented in table 3 . Of the 26 spirometric COPD estimates, five studies excluded asthma [27, 48, 54, 57, 67]. A sensitivity analysis excluding these five studies did not appreciably affect the pooled prevalence estimate. The most common spirometric definitions were based upon criteria developed by the Global Initiative for Chronic Obstructive Lung Disease (GOLD; 13 estimates) [11]. A few studies used older versions of criteria published by the European Respiratory Society in 1995 (two estimates) [82] and American Thoracic Society (ATS) in 1987 (two estimates) [83]. All of these guidelines suggest that post-bronchodilator values should be used to define obstruction; however, only nine studies reported any type of post-bronchodilator measurement. Of 10 studies using GOLD criteria, only one study used post-bronchodilator values in the analysis [53]. There was wide variation in the reporting of spirometric quality control. For example, $81 \%$ of studies identified the type of spirometer used, but less than half $(46 \%)$ mentioned reproducibility criteria or made any mention of calibration procedures or frequency.

As expected, there was significant heterogeneity in all analyses. In order to address this, analyses limited to a diagnosis of COPD were performed, examining subgroups defined by age group, smoking status, sex, World Health Organization (WHO) region, study setting (urban versus rural) and study quality (table 4). Pooled prevalence estimates were significantly higher in strata containing persons aged $\geqslant 40 \mathrm{yrs}$ $(9.0 \%)$, smokers $(15.4 \%)$, males $(9.8 \%)$ and persons with urban residence $(10.2 \%)$. Prevalence did not vary significantly by WHO region, although these results should be interpreted with caution since only the European region had more than four 
TABLE 3 Nonduplicated pooled prevalence estimates of spirometric definitions for chronic obstructive pulmonary disease (COPD)

\begin{tabular}{|c|c|c|c|}
\hline & Spirometric criterion for defining COPD & Estimates $\mathbf{n}$ & $\begin{array}{c}\text { Pooled prevalence } \\
\%\end{array}$ \\
\hline GOLD (stage II), , & $\mathrm{FEV}_{1} / \mathrm{FVC}<0.70$ and $\mathrm{FEV}_{1}<80 \%$ pred & 7 & $5.5(3.3-9.0)$ \\
\hline European Respiratory Society (1995) & FEV 1 NC $<0.88 \%$ pred (males); FEV $1 / N C<89 \%$ pred (females) & 2 & $9.9(8.1-12.0)$ \\
\hline American Thoracic Society (1987) & $\mathrm{FEV}_{1} / \mathrm{FVC}<0.75$ & 2 & $21.8(4.7-61.4)$ \\
\hline Other spirometric criteria & Various & 12 & $7.9(5.6-11.0)$ \\
\hline Overall & & 26 & $9.2(7.7-11.0)$ \\
\hline
\end{tabular}

Pooled prevalences are presented as pooled prevalence estimate (95\% confidence interval). GOLD: Global Initiative for Chronic Obstructive Lung Disease; FEV1: forced expiratory volume in one second; FVC: forced vital capacity; \% pred: percentage of the predicted value; VC: (slow) vital capacity. * : definition consistent with the 1997 British Thoracic Society definition cited by one study [58]; : guidelines specify that post-bronchodilator values should be used to determine obstruction; however, only one study using GOLD stage II criteria [53] and one using 1995 ERS criteria [54] used post-bronchodilator testing. Heterogeneity within each stratum, as calculated by the $Q$ statistic, was significant for all strata $(p<0.05)$. The categories for individual spirometric estimates (e.g. GOLD I and GOLD II) are not mutually exclusive. Thus a single study could report multiple prevalence estimates based on different diagnostic criteria. For the overall pooled value, if a single study reported multiple estimates, only one estimate was used, which was selected based on the hierarchy presented in Appendix 3.

TABLE 4 Nonduplicated pooled prevalence estimates for chronic obstructive pulmonary disease by category

\begin{tabular}{|c|c|c|c|c|c|c|}
\hline & Estimates & Cases & Total population & Prevalence \% & Pooled prevalence $\%$ & p-value ${ }^{\#}$ \\
\hline Overall & 37 & 111261 & 4123646 & $8.9(2.1-26.4)$ & $7.6(6.0-9.5)$ & \\
\hline$<40 \mathrm{yrs}$ & 9 & 1074 & 25362 & $2.7(0.8-10.6)$ & $3.1(1.8-5.0)$ & $<0.0001$ \\
\hline$\geqslant 40 \mathrm{yrs}$ & 34 & 4933 & 46095 & $9.7(1.8-29.7)$ & $9.9(8.2-11.8)$ & \\
\hline $40-64$ yrs & 23 & 2793 & 30942 & $7.6(1.8-28.7)$ & $8.2(6.5-10.3)$ & \\
\hline Smoker & 17 & 3133 & 24122 & $15.2(5.1-39.7)$ & $15.4(11.2-20.7)$ & $<0.0001$ \\
\hline Ex-smoker & 16 & 1240 & 14521 & $12.7(2.8-27.7)$ & $10.7(8.1-14.0)$ & \\
\hline Never-smoker & 16 & 1235 & 32542 & $3.9(0.7-14.6)$ & $4.3(3.2-5.7)$ & \\
\hline \multicolumn{7}{|l|}{ Sex } \\
\hline Male & 27 & 16480 & 327293 & $11.0(2.5-28.0)$ & $9.8(8.0-12.1)$ & 0.0002 \\
\hline Eastern Mediterranean & 0 & 0 & 0 & & & \\
\hline Europe & 28 & 104773 & 4015455 & $8.3(2.1-26.4)$ & $7.4(5.9-9.3)$ & \\
\hline South-East Asia & $2^{+}$ & 747 & 6044 & $12.5(7.1-17.9)$ & $11.4(4.4-26.4)$ & \\
\hline Western Pacific & $4^{\S}$ & 3075 & 74548 & $10.6(3.0-18.2)$ & $9.0(3.0-24.1)$ & \\
\hline \multicolumn{7}{|l|}{ Study setting } \\
\hline Urban & 12 & 4096 & 44153 & $10.3(3.6-26.4)$ & $10.2(7.4-13.9)$ & 0.0438 \\
\hline Mixed & 21 & 105571 & 4075965 & $4.9(2.3-17.8)$ & $6.1(4.9-7.7)$ & \\
\hline Rural & 4 & 437 & 3482 & $8.4(2.1-18.3)$ & $8.0(3.9-15.8)$ & \\
\hline \multicolumn{7}{|l|}{ Study quality } \\
\hline Good & 15 & 23539 & 583658 & $6.8(3.2-18.3)$ & $6.8(5.2-8.9)$ & 0.6958 \\
\hline Average & 13 & 6434 & 124960 & $7.1(2.1-14.6)$ & $6.7(4.5-9.8)$ & \\
\hline Poor & 9 & 80131 & 3414982 & $10.5(2.3-26.4)$ & $9.9(4.2-21.6)$ & \\
\hline
\end{tabular}

Data are presented as $\mathrm{n}$. Prevalences are presented as median (range) and pooled prevalences as pooled prevalence estimate (95\% confidence interval). WHO: World


and South Korea. Heterogeneity within each stratum, as calculated by the $Q$ statistic, was significant for all strata with more than one estimate $(p<0.0001)$. 
estimates. Results were not appreciably affected by study quality.

\section{DISCUSSION}

The present report provides the first quantitative summary of the world literature on COPD prevalence, with high-quality estimates for COPD in important subgroups defined by age, smoking status and sex. The available data suggest that the prevalence of physiologically defined COPD in adults aged $\geqslant 40$ yrs is $9-10 \%$. This is consistent with the range of $4-10 \%$ cited in a previous qualitative review [7]. These results highlight the lack of good quality prevalence data from outside Europe and North America. It was not possible to locate any spirometric studies reporting COPD prevalence in the African or Eastern Mediterranean regions. In addition, only three or four reports each were found from the American, South-East Asian and Western Pacific regions. Much of the available literature from Africa is limited to $\mathrm{CB}$, and has been well summarised by CHAN-YeUng et al. [8]. TAN et al. [84] used a statistical model to estimate the prevalence of moderate-tosevere COPD in the Asia-Pacific region, with a regional estimate of $6.3 \%$ and projected country-specific rates of 3.5$6.7 \%$, which are generally consistent with the pooled estimates presented here.

Significant heterogeneity was found in prevalence measures, which was incompletely explained by subgroup analyses. Although prevalence differences among countries are not unexpected, it is important to explore potential sources of heterogeneity. One such source is the diversity of diagnostic definitions. Clinical diagnoses or, more properly, patientreported diagnoses clearly appear to underestimate disease prevalence. Spirometry can provide better estimates, but is not without limitations. Even among studies that used spirometric definitions of COPD, the most common diagnostic criterion, GOLD stage II, was used in only a quarter of studies. Pooled prevalence estimates varied widely by definition, from 5.5\% (GOLD stage II) to $>20 \%$ (ATS, 1987), a wider range than might be expected from methodological differences alone [7]. However, the efforts of the GOLD are clearly having an effect. The definition proposed by the GOLD, forced expiratory volume in one second (FEV1)/forced vital capacity (FVC) of $<0.70$, has been adopted as an epidemiological case definition by the Burden of Obstructive Lung Disease (BOLD) initiative and the Latin-American Project for the Investigation of Pulmonary Obstruction (PLATINO), both of which measure COPD prevalence in multiple countries $[6,85]$. Although new prevalence measurements have been produced by both groups, they were not available in print during the period covered by this review. Movements toward a consistent spirometric criterion should help reduce the diversity reflected in the literature $[11,86]$.

Some of the variation in COPD prevalence may reflect technical issues related to the collection of spirometric data. At the most basic level, the quality of spirometric testing can affect the assignment of a diagnostic label. An inadequate FVC, for example, can lead to overestimation of the FEV1/FVC ratio and thus underestimation of prevalence. It was not possible to grade the quality of spirometry, but the reporting of spirometric quality criteria, which varied widely, was examined. Both the BOLD initiative and PLATINO have embraced systematic quality control criteria for spirometry as an essential component of their programmes [6, 85]. Between-study differences in the handling of substandard spirometric results may also affect prevalence estimates. The likelihood of producing reproducible spirometric measurements decreases with increasing severity of lung disease [87]. Thus the exclusion of nonreproducible tests is likely to selectively exclude a higher proportion of persons with obstructive disease, leading to prevalence underestimation. Another source of variation may be the use of post-bronchodilator lung function testing. Most of the major COPD guidelines indicate that post-bronchodilator results should be used to identify obstruction. From the present spirometric studies, however, only approximately a third administered a bronchodilator to any of the subjects tested, and half of these only gave a bronchodilator to subjects with abnormal results during the initial reading. The impact of post-bronchodilator testing on COPD prevalence estimates can be substantial [88].

Other important sources of heterogeneity include known rate relationships within epidemiologically important subgroups, with age strata perhaps the most important. There was a wide diversity of age ranges across the studies in the present review, and few papers reported summary age statistics or age distribution data that might have allowed mathematically robust age comparisons. As a result, the definition for age subgroups was imprecise. The cut-off at age 40 yrs was chosen to reflect the methodology proposed by the BOLD initiative [6]. Indeed, the pooled estimate of $10 \%$ for adults aged $\geqslant 40 \mathrm{yrs}$ may be the most useful parameter to emerge from the present study.

Subgroup analyses also showed that, as expected, rates were higher in smokers, males and urban residents. However, reporting of prevalence estimates for these subgroups was imperfect. For example, only $73 \%$ of studies provided separate prevalence estimates for males and females, and $46 \%$ provided separate estimates for smokers. Since these subgroups were not the primary interest, however, several studies that limited their study population to smokers alone were excluded. Similarly, several studies limited to various high-risk occupational settings were excluded. It was not possible to examine true interactions between age, sex and smoking status due to the limitations of the meta-analytical technique, as well as the limited details of results reported in most publications.

In order to avoid double-counting, a hierarchical system was used to choose between multiple estimates drawn from the same population. In doing so, assumptions were made that might have introduced bias. In order to evaluate this, these hierarchical results were compared with models using the lowest (conservative) and highest (liberal) prevalence estimate within each subgroup (data not shown). In most subgroups, the pooled prevalence estimate for the hierarchical model lay between the conservative and liberal estimates.

Articles published prior to 1990 were excluded in order to avoid temporal bias in smoking/COPD trends, which meant excluding several population-based prevalence estimates from the USA that were conducted in the 1960s, 1970s and 1980s. In addition, although the US National Health Interview Survey is conducted annually, only the most recent publication from 
the survey was included. As a result, the results over-represent European studies in comparison with North American studies.

\section{Conclusions}

Although prevalence estimates for chronic obstructive pulmonary disease are being published for many areas of the world, high-quality estimates are lacking for key regions, and differences in measurement methodology hinder meaningful comparisons of published studies. Efforts by groups such as the Global Initiative for Chronic Obstructive Lung Disease, Burden of Obstructive Lung Disease initiative and the LatinAmerican Project for the Investigation of Pulmonary Obstruction may help standardise chronic obstructive pulmonary disease measurements, thus improving understanding of the global burden of this major disease.

\section{REFERENCES}

1 Calverley PM, Walker P. Chronic obstructive pulmonary disease. Lancet 2003; 362: 1053-1061.

2 Sullivan SD, Ramsey SD, Lee TA. The economic burden of COPD. Chest 2000; 117: 5S-9S.

3 Ferrer M, Alonso J, Morera J, et al. Chronic obstructive pulmonary disease stage and health-related quality of life. Ann Intern Med 1997; 127: 1072-1079.

4 Murray CJ, Lopez AD. Alternative projections of mortality and disability by cause 1990-2020: Global Burden of Disease Study. Lancet 1997; 349: 1498-1504.

5 Feenstra TL, van Genugten ML, Hoogenveen RT, Wouters EF, Rutten-van Mölken MP. The impact of aging and smoking on the future burden of chronic obstructive pulmonary disease: a model analysis in the Netherlands. Am J Respir Crit Care Med 2001; 164: 590-596.

6 Buist AS, Vollmer WM, Sullivan SD, et al. The Burden of Obstructive Lung Disease initiative (BOLD): rationale and design. J COPD 2005; 2: 277-283.

7 Halbert RJ, Isonaka S, George D, Iqbal A. Interpreting COPD prevalence estimates: what is the true burden of disease? Chest 2003; 123: 1684-1692.

8 Chan-Yeung M, Ait-Khaled N, White N, Ip MS, Tan WC. The burden and impact of COPD in Asia and Africa. Int $J$ Tuberc Lung Dis 2004; 8: 2-14.

9 Snider GL. Nosology for our day: its application to chronic obstructive pulmonary disease. Am J Respir Crit Care Med 2003; 167: 678-683.

10 Iqbal A, Schloss S, George D, Isonaka S. Worldwide guidelines for chronic obstructive pulmonary disease: a comparison of diagnosis and treatment recommendations. Respirology 2002; 7: 233-239.

11 Global Initiative for Chronic Obstructive Lung Disease. Global Strategy for the Diagnosis, Management, and Prevention of Chronic Obstructive Pulmonary Disease. http:/ / www.goldcopd.com/Guidelineitem.asp? $11=2 \& 12=$ $1 \&$ intId=989 Date last updated: August 2005. Date last accessed: June 2006.

12 Celli BR, Halbert RJ, Isonaka S, Schau B. Population impact of different definitions of airway obstruction. Eur Respir J 2003; 22: 268-273.

13 Hedges LV, Olkin I. Statistical Methods for Meta-Analysis. Orlando, FL, Academic Press, 1985.
14 Cochran BG. The combination of estimates from different experiments. Biometrics 1954; 10: 101-129.

15 Higgins JP, Thompson SG. Quantifying heterogeneity in a meta-analysis. Stat Med 2002; 21: 1539-1558.

16 Ehrlich RI, White N, Norman R, et al. Predictors of chronic bronchitis in South African adults. Int J Tuberc Lung Dis 2004; 8: 369-376.

17 Menezes AM, Victora CG, Rigatto M. Prevalence and risk factors for chronic bronchitis in Pelotas, RS, Brazil: a population-based study. Thorax 1994; 49: 1217-1221.

18 Menezes AM, Victora CG, Rigatto M. Chronic bronchitis and the type of cigarette smoked. Int J Epidemiol 1995; 24: 95-99.

19 Chen Y, Breithaupt K, Muhajarine N. Occurrence of chronic obstructive pulmonary disease among Canadians and sex-related risk factors. J Clin Epidemiol 2000; 53: 755-761.

20 Lethbridge-Cejku M, Schiller JS, Bernadel L. Summary health statistics for U.S. adults: National Health Interview Survey, 2002. Vital Health Stat 2004; 10: 1-151.

21 Mannino DM, Gagnon RC, Petty TL, Lydick E. Obstructive lung disease and low lung function in adults in the United States: data from the National Health and Nutrition Examination Survey, 1988-1994. Arch Intern Med 2000; 160: 1683-1689.

22 Turkeltaub PC, Gergen PJ. Prevalence of upper and lower respiratory conditions in the US population by social and environmental factors: data from the second National Health and Nutrition Examination Survey, 1976 to 1980 (NHANES II). Ann Allergy 1991; 67: 147-154.

23 Eisner MD, Yelin EH, Trupin L, Blanc PD. The influence of chronic respiratory conditions on health status and work disability. Am J Public Health 2002; 92: 1506-1513.

24 Golshan M, Barahimi H, Nasirian K. Prevalence of chronic bronchitis and chronic respiratory symptoms in adults over the age of 35 years in Isfahan, Iran in 1998. Respirology 2001; 6: 231-235.

25 Vondra V, Reisova M, Prazakova J, et al. Výskyt bronchiálního astmatu, chronické bronchitidy a bronchiální hyperreaktivity u dospělých obyvatel Prahy 8. [Prevalence of bronchial asthma, chronic bronchitis and bronchial hyperreactivity in the adult population in the Prague 8 district]. Cas Lek Cesk 1993; 132: 113-118.

26 Vondra V, Reisova M, Petrik P, Skulova Z, Maly M. Prevalence bronchiálního astmatu, chronické bronchitidy a alergických rým v jihomoravském. [Prevalence of bronchial asthma, chronic bronchitis and allergic rhinitis in a South Moravian District]. Vnitr Lek 1994; 40: 21-25.

27 Lange P. Development and prognosis of chronic obstructive pulmonary disease with special reference to the role of tobacco smoking. An epidemiologic study. Dan Med Bull 1992; 39: 30-48.

28 Lange P, Groth S, Nyboe J, et al. Chronic obstructive lung disease in Copenhagen: cross-sectional epidemiological aspects. J Intern Med 1989; 226: 25-32.

29 Jannus-Pruljan L, Meren M, Polluste J, et al. Postal survey on asthma, chronic bronchitis and respiratory symptoms among adult Estonians and non-Estonians (FinEsS-study). Eur J Public Health 2004; 14: 114-119.

30 Meren M, Jannus-Pruljan L, Loit HM, et al. Asthma, chronic bronchitis and respiratory symptoms among 
adults in Estonia according to a postal questionnaire. Respir Med 2001; 95: 954-964.

31 Hedman J, Kaprio J, Poussa T, Nieminen MM. Prevalence of asthma, aspirin intolerance, nasal polyposis and chronic obstructive pulmonary disease in a population-based study. Int J Epidemiol 1999; 28: 717-722.

32 Isoaho R, Puolijoki H, Huhti E, et al. Prevalence of chronic obstructive pulmonary disease in elderly Finns. Respir Med 1994; 88: 571-580.

33 Lindstrom M, Kotaniemi J, Jonsson E, Lundback B. Smoking, respiratory symptoms, and diseases: a comparative study between Northern Sweden and Northern Finland: report from the FinEsS study. Chest 2001; 119: 852-861.

34 von Hertzen L, Reunanen A, Impivaara O, Malkia E, Aromaa A. Airway obstruction in relation to symptoms in chronic respiratory disease - a nationally representative population study. Respir Med 2000; 94: 356-363.

35 Huchon GJ, Vergnenegre A, Neukirch F, et al. Chronic bronchitis among French adults: high prevalence and underdiagnosis. Eur Respir J 2002; 20: 806-812.

36 Nejjari C, Tessier JF, Letenneur L, et al. Determinants of chronic bronchitis prevalence in an elderly sample from south-west of France. Monaldi Arch Chest Dis 1996; 51: 373-379.

37 Cricelli C, Mazzaglia G, Samani F, et al. Prevalence estimates for chronic diseases in Italy: exploring the differences between self-report and primary care databases. J Public Health Med 2003; 25: 254-257.

38 La Vecchia C, Decarli A, Negri E, Ferraroni M, Pagano R. Height and the prevalence of chronic disease. Rev Epidemiol Sante Publique 1992; 40: 6-14.

39 Viegi G, Pedreschi M, Baldacci S, et al. Prevalence rates of respiratory symptoms and diseases in general population samples of North and Central Italy. Int J Tuberc Lung Dis 1999; 3: 1034-1042.

40 Viegi G, Pedreschi M, Pistelli F, et al. Prevalence of airways obstruction in a general population: European Respiratory Society vs American Thoracic Society definition. Chest 2000; 117: Suppl. 2, 339S-345S.

41 Donato F, Pasini GF, Buizza MA, et al. Tobacco smoking, occupational exposure and chronic respiratory disease in an Italian industrial area. Monaldi Arch Chest Dis 2000; 55: 194-200.

42 Cerveri I, Accordini S, Corsico A, et al. Chronic cough and phlegm in young adults. Eur Respir J 2003; 22: 413-417.

43 Lesauskaite V. Comparison of the prevalence of chronic respiratory symptoms in the population of Kaunas and five rural region centres. Acta Med Lituanica 1998; 5: 128-132.

44 Cerveri I, Accordini S, Verlato G, et al. Variations in the prevalence across countries of chronic bronchitis and smoking habits in young adults. Eur Respir J 2001; 18: 85-92.

45 de Marco R, Accordini S, Cerveri I, et al. An international survey of chronic obstructive pulmonary disease in young adults according to GOLD stages. Thorax 2004; 59: 120-125.

46 Bakke PS, Baste V, Hanoa R, Gulsvik A. Prevalence of obstructive lung disease in a general population: relation to occupational title and exposure to some airborne agents. Thorax 1991; 46: 863-870.

47 Niepsuj G, Kozielski J, Niepsuj K, et al. Przewlekła obturancyjna choroba płuc u mieszkańców miasta Zabrza. [Chronic obstructive pulmonary disease in inhabitants of Zabrze]. Wiad Lek 2002; 55: Suppl. 1, 354-359.

48 Plywaczewski R, Bednarek M, Jonczak L, Zielinski J. Częstość występowania POChP wśród mieszkańców prawobrzeżnej Warszawy. [Prevalence of COPD in Warsaw population]. Pneumonol Alergol Pol 2003; 71: 329-335.

49 Dutu S, Paun G. Prevalenţa unor simptome respiratorii, a astmului bronşic şi a bronşitei cronice (simple şi obstructive) într-un eşantion reprezentatic pentru o populaţie adultă rurală. [The prevalence of respiratory symptoms, bronchial asthma and chronic bronchitis (simple and obstructive) in a representative sample of the adult rural population]. Pneumoftiziologia 1998; 47: 151-160.

50 Voinov AI., Lobanov AА. ЭпИДемиология хронических обструктивных заболевании Легких. [Epidemiology of chronic obstructive pulmonary diseases]. Med Tr Prom Ekol 2003; 23-25.

51 Hawthorne VM, Watt GC, Hart CL, et al. Cardiorespiratory disease in men and women in urban Scotland: baseline characteristics of the Renfrew/Paisley (midspan) study population. Scott Med J 1995; 40: 102-107.

52 Brotons B, Perez JA, Sanchez-Toril F, et al. Prevalencia de la enfermedad pulmonar obstructiva crónica y del asma. Estudio transversal. [The prevalence of chronic obstructive pulmonary disease and asthma. A cross-sectional study]. Arch Bronconeumol 1994; 30: 149-152.

53 Jaen A, Ferrer A, Ormaza I, et al. Prevalencia de bronquitis crónica, asma y obstrucción al flujo aéreo en una zona urbano-industrial de Cataluña. [Prevalence of chronic bronchitis, asthma and airflow limitation in an urbanindustrial area of Catalonia]. Arch Bronconeumol 1999; 35 122-128.

54 Pena VS, Miravitlles M, Gabriel R, et al. Geographic variations in prevalence and underdiagnosis of COPD: results of the IBERPOC multicentre epidemiological study. Chest 2000; 118: 981-989.

55 Subirats BE, Vila BL, Vila ST, et al. Prevalencia de enfermedades respiratorias en una población rural del norte de Cataluña: La Cerdanya. [Prevalence of respiratory diseases in a rural population in the north of Catalonia: la Cerdanya]. Med Clin (Barc) 1994; 103: 481-484.

56 Bjornsson E, Plaschke P, Norrman E, et al. Symptoms related to asthma and chronic bronchitis in three areas of Sweden. Eur Respir J 1994; 7: 2146-2153.

57 Hasselgren M, Arne M, Lindahl A, Janson S, Lundback B. Estimated prevalences of respiratory symptoms, asthma and chronic obstructive pulmonary disease related to detection rate in primary health care. Scand J Prim Health Care 2001; 19: 54-57.

58 Lindstrom M, Jonsson E, Larsson K, Lundback B. Underdiagnosis of chronic obstructive pulmonary disease in Northern Sweden. Int J Tuberc Lung Dis 2002; 6: 76-84.

59 Lundback B, Nystrom L, Rosenhall L, Stjernberg N. Obstructive lung disease in Northern Sweden: respiratory symptoms assessed in a postal survey. Eur Respir J 1991; 4: 257-266. 
60 Lundback B, Stjernberg N, Nystrom L, et al. An interview study to estimate prevalence of asthma and chronic bronchitis. The Obstructive Lung Disease in Northern Sweden study. Eur J Epidemiol 1993; 9: 123-133.

61 Montnemery P, Adelroth E, Heuman K, et al. Prevalence of obstructive lung diseases and respiratory symptoms in Southern Sweden. Respir Med 1998; 92: 1337-1345.

62 Larsson L, Boethius G, Uddenfeldt M. Differences in utilisation of asthma drugs between two neighbouring Swedish provinces: relation to prevalence of obstructive airway disease. Thorax 1994; 49: 41-49.

63 Martin BW, Ackermann-Liebrich U, Leuenberger P, et al. SAPALDIA: methods and participation in the crosssectional part of the Swiss Study on Air Pollution and Lung Diseases in Adults. Soz Praventivmed 1997; 42: 67-84.

64 Leuenberger P. Pollution de l'air en Suisse et maladies respiratoires chez l'adulte. Résultats preliminaries de la partie transversale de l'étude Sapaldia. [Air pollution in Switzerland and respiratory diseases in adults. Results of a preliminary study of the cross-sectional part of the SAPALDIA study]. Schweiz Rundsch Med Prax 1995; 84: 1096-1100.

65 Leuenberger P, Kunzli N, Ackermann-Liebrich U, et al. Etude Suisse sur la pollution de l'air et les maladies respiratoires chez l'adulte (SAPALDIA). [Swiss Study on Air Pollution and Lung Diseases in Adults (SAPALDIA)]. Schweiz Med Wochenschr 1998; 128: 150-161.

66 Cetinkaya F, Gulmez I, Aydin T, et al. Prevalence of chronic bronchitis and associated risk factors in a rural area of Kayseri, Central Anatolia, Turkey. Monaldi Arch Chest Dis 2000; 55: 189-193.

67 Dickinson JA, Meaker M, Searle M, Ratcliffe G. Screening older patients for obstructive airways disease in a semirural practice. Thorax 1999; 54: 501-505.

68 Soriano JB, Maier WC, Egger P, et al. Recent trends in physician diagnosed COPD in women and men in the UK. Thorax 2000; 55: 789-794.

69 Renwick DS, Connolly MJ. Prevalence and treatment of chronic airways obstruction in adults over the age of 45 . Thorax 1996; 51: 164-168.

70 Akhtar MA, Latif PA. Prevalence of chronic bronchitis in urban population of Kashmir. J Indian Med Assoc 1999; 97: 365-6, 369.

71 Qureshi KA. Domestic smoke pollution and prevalence of chronic bronchitis/asthma in a rural area of Kashmir. Indian J Chest Dis Allied Sci 1994; 36: 61-72.

72 Ray D, Abel R, Selvaraj KG. A 5-yr prospective epidemiological study of chronic obstructive pulmonary disease in rural South India. Indian J Med Res 1995; 101: 238-244.

73 Kumar R, Sharma M, Srivastva A, et al. Association of outdoor air pollution with chronic respiratory morbidity in an industrial town in Northern India. Arch Environ Health 2004; 59: 471-477.

74 Maranetra KN, Chuaychoo B, Dejsomritrutai W, et al. The prevalence and incidence of COPD among urban older persons of Bangkok Metropolis. J Med Assoc Thai 2002; 85: 1147-1155.

75 Abramson M, Matheson M, Wharton C, Sim M, Walters EH. Prevalence of respiratory symptoms related to chronic obstructive pulmonary disease and asthma among middle aged and older adults. Respirology 2002; 7: 325-331.

76 Chen $\mathrm{P}, \mathrm{Yu}$ ES, Zhang $\mathrm{M}$, et al. ADL dependence and medical conditions in Chinese older persons: a populationbased survey in Shanghai, China. J Am Geriatr Soc 1995; 43: 378-383.

77 Cheng X, Li J, Zhang Z. [Analysis of basic data of the study on prevention and treatment of COPD and chronic cor pulmonale]. Zhonghua Jie He He Hu Xi Za Zhi 1998; 21: 749-752.

78 Lai CK, Ho SC, Lau J, et al. Respiratory symptoms in elderly Chinese living in Hong Kong. Eur Respir J 1995; 8: 2055-2061.

79 Fukuchi Y, Nishimura M, Ichinose M, et al. COPD in Japan: the Nippon COPD Epidemiology Study. Respirology 2004; 9: 458-465.

80 Shin C, In KH, Shim JJ, et al. Prevalence and correlates of airway obstruction in a community-based sample of adults. Chest 2003; 123: 1924-1931.

81 Golshan M, Faghihi M, Marandi MM. Indoor women jobs and pulmonary risks in rural areas of Isfahan, Iran, 2000. Respir Med 2002; 96: 382-388.

82 Siafakas NM, Vermeire P, Pride NB, et al. Optimal assessment and management of chronic obstructive pulmonary disease (COPD). Eur Respir J 1995; 8: 1398-1420.

83 American Thoracic Society. Standards for the diagnosis and care of patients with chronic obstructive pulmonary disease (COPD) and asthma. Am Rev Respir Dis 1987; 136: 225-244.

84 Tan WC, Seale P, Chaoenrantanakul S, et al. Chronic obstructive pulmonary disease (COPD) prevalence in 7 Asian countries: projections based on the COPD prevalence model. Am J Respir Crit Care Med 2001; 163: A81.

85 Menezes AM, Perez-Padilla R, Jardim JR, et al. Chronic obstructive pulmonary disease in five Latin American cities (the PLATINO study): a prevalence study. Lancet 2005; 366: 1875-1881.

86 Celli BR, MacNee W. Standards for the diagnosis and treatment of patients with COPD: a summary of the ATS/ ERS position paper. Eur Respir J 2004; 23: 932-946.

87 Mannino DM, Buist AS, Petty TL, Enright PL, Redd SC. Lung function and mortality in the United States: data from the First National Health and Nutrition Examination Survey follow up study. Thorax 2003; 58: 388-393.

88 Johannessen A, Omenaas ER, Bakke PS, Gulsvik A. Implications of reversibility testing on prevalence and risk factors for chronic obstructive pulmonary disease: a community study. Thorax 2005; 60: 842-847. 


\section{APPENDIX 1: COPD PREVALENCE LITERATURE SEARCH RESULTS}

\section{TABLE 5 Non-English language articles}

Search Most recent query

No.

Results

978

Search: English language; limits: publication date 1990-2004 6166153

Search: No. 4 AND No. 5; limits: publication date 1990-2004 5265

Search: No. 1 OR No. 2 OR No. 3; limits: publication date 1990-2004 30682

Search: epidemiology OR prevalence OR incidence; limits: publication date 1990-2004 727562

Search: emphysema OR airway obstruction; limits: publication date 1990-2004 17177

Search: bronchitis chronic OR bronchitis, chronic OR chronic bronchitis; limits: 3050

$$
\text { publication date 1990-2004 }
$$

Search: pulmonary disease, chronic obstructive OR pulmonary disease chronic

obstructive OR chronic obstructive pulmonary disease OR COPD; field: all fields;

15158

COPD: chronic obstructive pulmonary disease.

\section{TABLE 6 English language articles}

\section{Search}

No.

Most recent query
Results

n

4486

24963

635624

14171

2025

12331
Search: No. 1 OR No. 2 OR No. 3; limits: publication date 1990-2004, English Search: epidemiology OR prevalence OR incidence; limits: publication date 1990-2004, English

Search: emphysema OR airway obstruction; limits: publication date 1990-2004, English

Search: bronchitis chronic OR bronchitis, chronic OR chronic bronchitis; limits: publication date 1990-2004, English

Search: pulmonary disease, chronic obstructive OR pulmonary disease chronic obstructive OR chronic obstructive pulmonary disease OR COPD; field: all fields; limits: publication date

1990-2004, English

COPD: chronic obstructive pulmonary disease.

\section{APPENDIX 2: CRITERIA FOR STUDY QUALITY ASSESSMENT}

\section{TABLE 7 Criteria for study quality assessment}

\section{Domain}

Study design

Data analysis

\section{Scoring ${ }^{\#}$}

Age range: adequate age range for study population (respondents' minimum age 35-60 yrs) Inclusion/exclusion criteria: appropriate exclusion criteria (e.g. did not exclude patients with asthma or prior pulmonary diagnoses)

Prevalence study: primary purpose of study to determine COPD (or COPD as one of several chronic diseases) prevalence and study methods reflect importance of COPD

Demographics: must give age, sex and smoking distribution of sample

Subgroup analysis: must contain at least two of three subgroup prevalence analyses for above demographic variables

Description of nonresponders: must contain some analysis of nonresponders beyond response rate

COPD: chronic obstructive pulmonary disease. * : one point was awarded for each scoring criterion; 0-1 points: poor; 2 points: average; 3 points: good 


\section{APPENDIX 3: HIERARCHICAL RANKING SYSTEM}

\section{TABLE 8 Hierarchical ranking system}

Spirometry: not stated Physician diagnosis ${ }^{\#}$

Patient-reported diagnosis (previous physician diagnosis) ${ }^{\#}$

Patient-reported diagnosis (self-report) ${ }^{\#}$

Physical/radiographic findings

Chronic bronchitis

Emphysema
Chronic productive cough

Patient-reported diagnosis (previous physician diagnosis)

Patient-reported diagnosis (self-report)

Physical/radiographic findings Patient-reported diagnosis (previous physician diagnosis)

Patient-reported diagnosis (self-report)

COPD: chronic obstructive pulmonary disease; GOLD: Global Initiative for Chronic Obstructive Lung Disease. * : includes diagnoses of chronic bronchitis/emphysema and $\mathrm{COPD}$ 